\title{
6 Renegotiating care from the local to global
}

\author{
Kayla Yurco
}

The COVID-19 pandemic arrived as I was writing, among other life and work pursuits, from my home in Virginia about the ethics of care related to the gendered nature of livestock management in southern Kenya. An early career scholar - in 2020, in my third year as a tenure-track Assistant Professor - I was working on a manuscript based on my dissertation fieldwork from a few years ago, while also nodding toward research questions and plans anew for the next few years. As the pandemic escalated and my capacity to make space for writing unraveled, so too did my understanding of care in the unprecedented world that emerged: care for myself, care for my loved ones, care for my students and colleagues, and care for the communities I was writing about halfway across the world.

Care is central to my focus in several ways. One of my major projects over the last decade in Kenya aims to unveil the gendered nature of livestock management in pastoralist communities and demonstrate how collaborative or conflictual livestock caretaking activities influence gender roles. This work recognizes that the existing rich body of literature on human-livestock-environment interactions in sub-Saharan Africa has tended to focus primarily on herding activities in rangelands where livestock graze under the supervision of men. Pastoralist women's caretaking roles at home have often been overlooked, yet, as my research demonstrates, they are integral to decision-making about household economies.

The care work that pastoralist women do is so significant. I've found that gendered intra-household relations, rather than grazing activities or household assets like herd size, determine food security and coping/adaptive strategies: namely, availability of milk resources for individuals within households. Moreover, gender relations within pastoralist households are coproduced through milking practices that emerge as women exercise their responsibilities to apportion milk (to hungry calves and hungry children, husbands, guests, and for occasional sales) and as men attempt to preside over these activities (implementing, subverting, or affirming rules and 


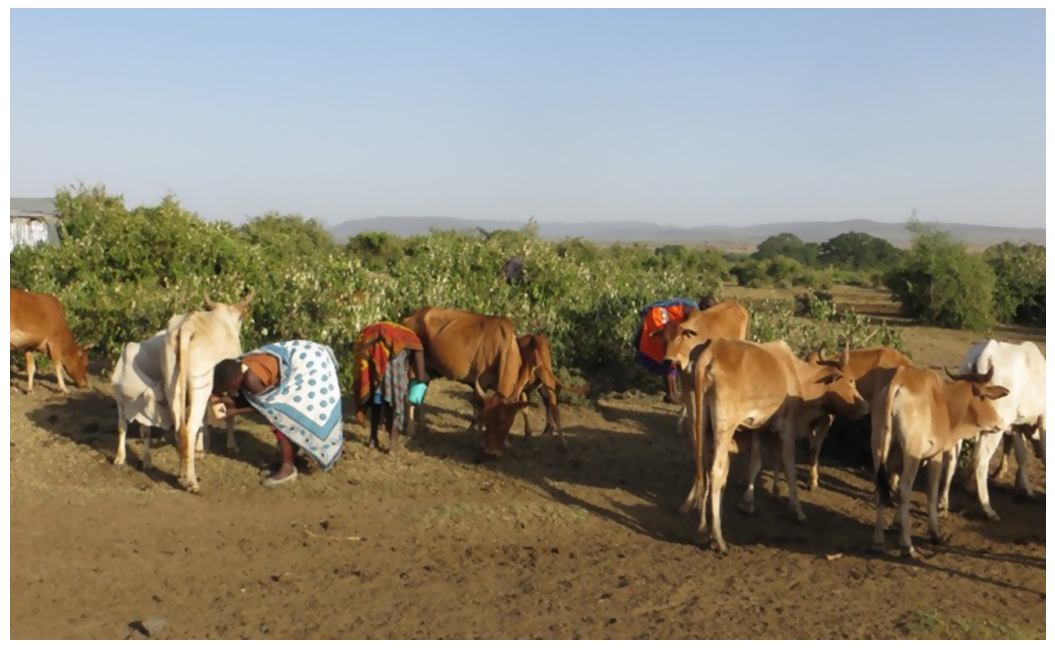

Figure 6.1 Morning milking events are important moments of care work (prepandemic) (Kayla Yurco).

norms of use). Women are also the holders of ethnoveterinary knowledge: with twice-daily milking activities, women physically connect with and observe the health of cows in dynamic milking events (Figure 6.1). These embodied moments of care inform women's difficult decisions about limited resources.

Through this care work, women navigate complex intra- and interhousehold dynamics associated with extended kin and, often, polygynous families. Livestock-based resources, for example, are not divided equitably among women within households. And even though women "control" milking activities, men control the allocation process of cattle to women. The degree to which women access milk through those milking activities is therefore influenced by the number of cows allocated to them, the number of dependents sharing resources, and the rigidity of rules associated with milking events and milk use (Figure 6.2). Mixed-methods data from hundreds of milking events and over 14 months of participant observation demonstrate that men's behaviors of favoritism to different wives, efforts by co-wives to cooperate or compete, and the extent of sharing for social capital and coping strategies within and across households all factor in to women's experiences of food security and well-being. Women hold great autonomy in their roles as livestock caretakers but still must navigate complicated household dynamics to enact that care. 


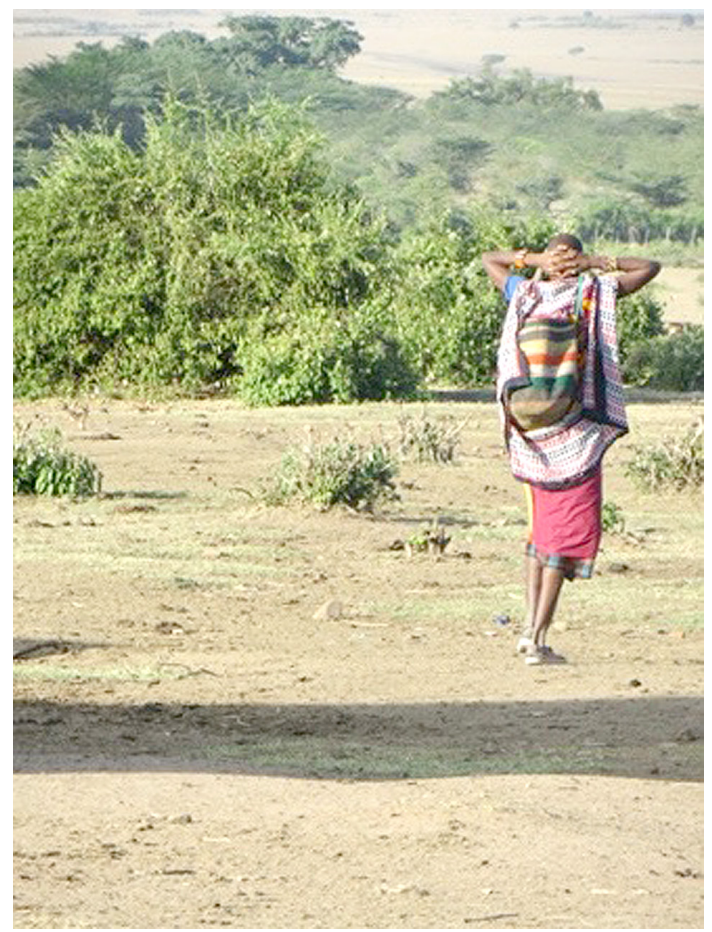

Figure 6.2 A woman carries milk away from her household for sharing and selling (pre-pandemic) (Kayla Yurco).

My findings align with efforts to expose the uncomfortable truth that deep-rooted patriarchal traditions ingrained in resource management practices in the Global South obscure the importance and complexity of women's labor. More uncomfortable is the truth that patriarchal traditions ingrained in academic discourse, theory, and methods also obscure the significance of women's labor. A clear example is the historical and normative conceptual focus on the household as a unit of analysis in agrarian settings, a focus that translates to limited availability of empirical, genderdisaggregated data from within households across the Global South. This is true even as evidence mounts for how resource use, access, and management decisions are differentiated within households along gendered lines worldwide.

The challenge here, and now more than ever, is that to understand gendered, embodied moments of care and their significance to women's lives, 
we need to follow Joni Seager's (2014) call to "lift the roof off the household" and see what makes a household work. Collecting gender-disaggregated data necessitates iterative feminist methodologies, collaboration with empowered research participants, and thoughtful reflections on positionality; i.e., it requires care. Practically, it also requires time actually spent in households. It requires so much time to understand the mundane, the ups and downs of the everyday, and the quirks that make us human - that which we might eventually codify as intra-household dynamics - time that allows us to process data points as characteristic of the collaborations and conflicts we all have across the proverbial dinner table.

Feminist methodologies, alongside a focus on ethics of care, have inspired new waves of gender-disaggregated research on intra-household dynamics. More and more studies, for example, point to the importance of women's care work as related to intra-household bargaining, negotiation, and patterns of decision-making for addressing social norms and structural inequities. Recognizing, valuing, and supporting care work seem critical for women's empowerment and intersectional food justice. As for my part in all of this: until last year, I've had the privilege to put my boots on the ground for a lot of time and often in my efforts to understand and write about these notions of care. Now, due to the global pandemic, I've had the privilege of wrestling with new notions of care from home. For instance: how can we keep caring and showing up for those we are writing about but cannot be with? And how can we care for ourselves in this uncertain era so that we can keep doing social and environmental justice work that empowers women in the gender-agriculture nexus now, and later?

Because there was, and is, much more to be done. While our momentum for this work has found a new obstacle in the arrival of the pandemic, what is more troubling are the ways that the pandemic amplifies preexisting gender inequities on communities, households, and individuals around the world.

\section{Pastoralists and COVID-19}

My field site in southern Kenya is just one of the many communities in the Global South where gender dynamics are coproduced with livestock management. According to the International Livestock Research Institute, 1.3 billion people depend mainly on livestock for their livelihoods worldwide. And it is estimated that more than half of the world's pastoralists reside in increasingly contested drylands in sub-Saharan Africa. Traditional pastoral mobility has been based on seasonal risk management in drylands, and pastoralists' short-term coping strategies and long-term adaptation strategies have been well studied across sub-Saharan Africa. Scholars of pastoralism 
have long understood the compound effects of climate change, policy shifts in land governance, and economic transitions that make pastoralists especially vulnerable in the modern world.

In reflecting on these vulnerabilities, some friends from southern Kenya have spoken of COVID-19 as a new, unprecedented threat; others have contextualized it as part of that compound threat. An important reality here is that pastoralism is predicated on movement and mobility - the very essence of what makes COVID-19 so challenging to control. It is no surprise that recent reports from across sub-Saharan Africa suggest that pandemicrelated restrictions on movements exacerbated existing challenges for pastoralists. In the early months of the pandemic, for example, Ministry of Health guidelines in Kenya meant to curtail the spread of the virus resulted in the closure of open-air livestock markets and limits on gatherings of people. With livestock serving as a main store of wealth for most pastoralists, the closure of markets made it difficult to transpose those resources to cash for other household needs. In the meantime, livestock continued to breed and require movement and care.

And for pastoralists who have diversified livelihoods through involvement in small businesses, tourism, or conservation work - like those in my study site near the Maasai Mara National Reserve, where nearly every household has at least one member involved in one of those industries the cessation of international flights, interruption of night-time travel, and closure of international borders amplified all of those challenges. As one of the premier wildlife safari destinations in East Africa (and as part of the tourism industry more broadly, an important contributor to Kenya's economy), this region felt the impacts of such closures strongly. Individuals and households who had responded to the last decade's challenges for a livestock-based economy (e.g., droughts, floods, and geopolitical tensions) by investing resources elsewhere struggled to move around to support their diversified household economies. Through all of this, labor burdens mounted, and dependence on livestock heightened.

But demands on labor have not been distributed equitably. A recent (2020) COVID-19 gender assessment report by UN Women confirms through countrywide surveys that women are disproportionately bearing pandemic-related burdens in Kenya, as is increasingly the case around the world. Early suspensions of movement affected the price and quantity of food supplies, straining women's responsibilities as provisioners of food. Nearly half of all households surveyed in Kenya reported a decline in food supplies in local markets and shops. Further, when schools were closed, families with children who relied on school feeding programs could no longer access these benefits; neither could they access education unless someone at home (often, women) could provide it. Given critical impacts of 
the pandemic on the informal sector where many women find wage work, more women lost their income than men. Women's access to sexual and reproductive healthcare has been impeded. And women have been pushed into more unpaid domestic and care work in their own homes and in those of family members and friends they support. Of course, the virus itself brought additional stressors to families with individuals who became ill or worse. The multilayered crisis is striking.

There are, however, a few bright spots. I'm learning from afar that the power of care work appears anew in a few places in southern Kenya's pastoralist communities, and elsewhere, and that adaptive efforts are already evident. Just as pastoralist women rely upon, and purposefully avoid, networks within and outside of their households for accessing livestock and milk, so too are they blurring public and private boundaries of households within their community in order to cope in the time of COVID-19. Care efforts are manifesting strongly at the community level. Women's groups - long recognized for providing a safe physical, emotional, and financial haven for women in times of conflict and hardship and in times of celebration and joy - remain vital during the pandemic. Participation there requires care work, too, but these groups materialize the kind of care for one another that, interestingly, works as a respite from the demands of everyday care at home.

Care work has been innovative in other spaces, too. Local conservancy associations are partnering with non-profit groups for recovery planning, working to ensure the longevity of a conservation land-leasing model that hopes to continue to support diversified local livelihoods in the region well into the future. Elsewhere in Kenya, new alliances of self-organizing community groups function as liaisons with local government officials to disseminate and share pandemic-related information. Telecommunications systems are being fast-tracked for veterinarians and livestock experts to provide advice for small-scale livestock-holders over mobile phones. While these tools are certainly useful in a time of social distancing and limited mobility, this mode of care work has real promise for the future. These systems have scalable impacts beyond COVID for pastoralists to manage day-to-day animal health challenges while balancing other familial and diversified professional responsibilities. Importantly, there is also the potential for these systems to help control future escalations of animal disease.

\section{Care ethics from and at home}

For now, I'm learning about these moments of harm and hope from afar. It's already the case that COVID-19 has ushered in significant efforts toward care-related research in the virtual sphere, with great emphasis on remote methodologies. Discussions are trending toward a reconceptualized 
ethics of care in scholarship and practice as we cope with the challenges of engaged, collaborative, and participatory partnerships in the time of crisis, often remotely. These discussions are difficult but remind me of the value of a gender transformative approach: it is adaptive and responsive. There is real resilience in the power of care.

As such, lately, I've felt that a focus on care, and the resilience it offers, might help us communicate and position these personal-political overlaps in this unprecedented complexity of care needs. This is about confronting individual privileges inherent in admitting how challenging it is to work on these topics during this difficult time while continuing to forge forward anew. Closer to home, I see (and feel) the everyday burdens on faculty continuing to mount. My care work involves a measured embrace of my own pandemic-related stresses and losses while still trying to show up as best I can for others I care so deeply about, locally and across the globe, and their stresses and losses. I see the need for recognizing care work everywhere, and I see the need for more care work everywhere, too.

Honest reflections on the power of care - the vulnerability of needing, expressing, and giving it - as individuals might give us the means to keep offering it toward our local, national, and global communities in this extraordinary time. Embracing the dynamic nature of care at a variety of scales might help us keep harnessing it toward ally-ship, organizing, action, and all else that is needed, especially to those experiencing heightened inequities in the agri-food system due to legacies of systemic marginalization, oppression, and violence.

Pre-pandemic, I didn't imagine that these questions of care would become the centralizing focus of my day-to-day energies. But care looks really different to me now. Many days, I try to hold space for care in discussions that pan out over text with the friends, colleagues, and research participants in Kenya who have made my career possible. COVID-19 has impacted their lives in ways I can only begin to understand from afar and has brought unprecedented challenges to their caretaking activities. Closer to home, a lot of my energy goes to holding space for local and community caretaking while asking difficult questions about my loved ones (e.g., is it care to visit my parents, or is it care to not visit them?). And with the fourth semester of teaching in the time of COVID looming ahead, my work now includes regular readings on the ethics of care in trauma-informed pedagogy and focused preparation to encourage self-care practices for my students in, and outside, the (virtual/hybrid/online) classroom. It is less clear to me to what degree this work manifests as care for my students or as self-care.

What is clear to me is that there is so much care work to be done. I'm aiming to contribute to the complexity, in part, by holding an honest space to reimagine and renegotiate my sense of, capacity for, and commitment to, 


\section{Kayla Yurco}

care. I'm warmly looking to learn from others struggling and succeeding with the same.

\section{References}

Seager, J. 2014. Background and Methodology for Gender Global Environmental Outlook. Nairobi, Kenya: United Nations Environment Programme.

UN Women-Kenya. 2020. COVID-19 Gender Assessment: Gender Perspective Kenya. Available at https://data.unwomen.org/publications/covid-19-gender -assessment-kenya. 